\title{
AUDIT SISTEM MANAGEMENT MUTU ISO 9001:2015 DAN SISTEM MANAJEMEN KEAMANAN PANGAN ISO 22000:2018 DI INDUSTRI OLEOKIMIA KAWASAN INDUSTRI MEDAN (KIM) MABAR
}

\author{
Pravil Mistryanto Tambunan ${ }^{1}$, Fariza Habibi ${ }^{2}$, Hajatina $^{3}$ \\ ${ }^{1)}$ Fakultas Farmasi dan Aproteker, Universitas Tjut Nyak Dhien, Program Studi Farmasi \\ ${ }^{2,3)}$ Akademi Perniagaan APIPSU, Program Studi Manajemen Perusahaan \\ Email author : praviltambunan91@gmail.com
}

\begin{abstract}
SO 9001:2015 Quality Management System and ISO 22000:2018 Food Safety Management System audit has been carried out in one of the oleochemical industries in the Medan Industrial Estate (KIM) Mabar. The audit is carried out in two stages, first on internal audit and second on visit by external certification body. The internal audit is coordinated by management representatives and carried out by 10 internal auditors whose competencies have been adjusted. The audit results are submitted to management through management review meetings and all agreed corrective actions are closed out by the relevant auditee. This research is a qualitative descriptive study, with the aim of comparing the results of internal audits with audits conducted by external certification bodies to test whether there are repeated findings caused by ineffective corrective actions. The results showed that from the results of the internal audit there were 21 findings related to documentation, policies, operational control, pest control, HACCP, and others. Meanwhile, the external audit only found problems with supplier control. The internal audit that has been carried out has proven to be effective so that the problems found internally are not repeated in the external audit, but it is necessary to strengthen the internal audit side related to supplier control.
\end{abstract}

Keywords: Internal Audit, Exsternal Audit, ISO 22000, ISO 9001, Oleokimia

\begin{abstract}
Abstrak
Telah dilakukan audit sistem manajemen mutu ISO 9001:2015 dan sistem manajemen keselamatan pangan ISO 22000:2018 di salah satu industri Oleokimia yang ada di Kawasan Industri Medan (KIM) Mabar. Audit dilakukan dalam dua tahapan yakni audit internal dan kunjungan oleh badan sertifikasi eksternal. Audit internal dikoordinasi oleh perwakilan manajemen (Management Representative) dan dilakukan oleh 10 internal auditor yang telah disesuaikan kompetensinya. Hasil audit disampaikan kepada manajemen melalui rapat tinjauan manajemen serta semua tindakan perbaikan yang telah disepakati dilaksanakan oleh auditee yang bersangkutan. Penelitian ini merupakan penelitian deskriftif kualitatif, dengan tujuan penelitian untuk membandingkankan hasil internal audit dengan audit yang dilaksanakan oleh badan sertifikasi eksternal untuk menguji apakah ada temuan berulang yang disebabkan kurang efektifnya tindakan koreksi. Hasil penelitian menunjukkan dari hasil internal audit didapati ada 21 temuan mengenai dokumentasi, kebijakan, operational control, pest control, HACCP, dan lain-lain. Sedangkan pada eksternal audit hanya ditemukan permasalahan pada pengendalian supplier. Internal audit yang dilakukan terbukti efektif sehingga permasalahan yang ditemukan secara internal tidak kembali berulang di eksternal audit, namun perlu dilakukan penguatan di sisi pemeriksaan internal audit terkait pengendalian supplier
\end{abstract}

Kata kunci: Audit Internal, Audit Eksternal, ISO 22000, ISO 9001, Oleochemical

\section{Pendahuluan}

Audit internal adalah kegiatan

konsultasi dan tanya jawab yang independen serta objektif yang dirancang untuk peningkatan operasi bisnis suatu organisasi. Program ini dapat membantu organisasi menggapai targetnya dengan menggunakan metode-metode yang sistematis dan disiplin 
untuk mengevaluasi serta meningkatkan efektivitas sistem manajemen berbasis risiko dan pengendalian operasional yang baik. Audit internal dapat mencapai tujuan ini dengan memberikan laporan serta rekomendasi berdasarkan analisis dan penilaian data dari suatu proses bisnis. Internal audit dilakukan dengan komitmen terhadap integritas dan akuntabilitas sehingga memberikan output berupa hasil penilaian kepada perwakilan manajemen dan manajemen senior sebagai pemegang kekuasaan tertinggi. Untuk mencapai tujuan ini, auditor internal dipekerjakan oleh suatu organisasi untuk melakukan aktivitas audit secara profesional.

Ruang lingkup sistem manajemen suatu organisasi mungkin luas dan mungkin melibatkan hal-hal seperti penataan proses bisnis, manajemen risiko, serta pengendalian sistem manajemen atas: efisiensi / efektivitas operasi (termasuk dalam hal ini pengamanan aset), ketepatan pada pelaporan keuangan dan manajemen, serta kepatuhan terhadap hukum dan peraturan serta persyaratan yang berlaku. Auditor internal tidak bertanggung jawab secara langsung atas pelaksanaan kegiatan yang sedang atau akan diauditnya. Mereka memberi pandangan kepada manajemen dan dewan direksi (atau perwakilan manajemen) tentang cara menjalankan tanggung jawab mereka dengan lebih baik. Sebagai hasil dari cakupan keterlibatan yang luas, auditor internal mungkin memiliki berbagai latar belakang pendidikan dan profesional yang lebih tinggi.

Audit internal dapat memberikan hasil yang efektif jika hasil yang ditampilkan kepada koordinator audit dan manajemen eksekutif menunjukkan jaminan yang mereka butuhkan, yaitu bahwa mereka dapat mengandalkan proses dan sistem organisasi untuk mengelola risiko serta pencapaian tujuannya. Hal ini berarti memberikan perlindungan untuk risiko terkait kelangsungan bisnis yang penting bagi perusahaan saat ini. Tentunya efektifitas ini bisa berbeda hasil tergantung pada faktorfaktor seperti banyaknya jumlah sampling, ruang, waktu serta kompetensi auditor yang melakukan audit.

Berdasarkan penjabaran di atas maka tujuan dari penelitian ini adalah membandingkan hasil internal audit dengan audit yang dilaksanakan oleh badan sertifikasi eksternal dan menguji apakah ada temuan berulang yang disebabkan kurang efektifnya tindakan koreksi 


\section{Tinjauan Pustaka}

ISO 9001 didefinisikan sebagai standar yang ditetapkan secara internasional mengenai persyaratan untuk sistem manajemen mutu (SMM). Organisasi mengimplementasikan standar ini untuk menunjukkan kemampuannya secara konsisten dalam menyediakan produk maupun jasa yang memenuhi persyaratan pelanggan serta peraturan. Standar ini pertama kali diterbitkan pada tahun 1987 oleh Organisasi Internasional untuk Standardisasi (ISO), yakni sebuah badan internasional yang berpusat di Jenewa, Swiss. Pada September 2015, versi terakhir ISO 9001 telah dirilis. Sedangkan ISO 22000 dirancang untuk mendukung bisnis dengan sistem manajemen keamanan pangan yang kuat. ISO 22000 mengambil pendekatan rantai pasokan yang luas untuk keamanan pangan, memberikan standar yang menjawab persyaratan dari pertanian hingga dihidangkan ke meja konsumen untuk seluruh industri rantai pasokan makanan.

ISO 19011 adalah standar internasional yang menetapkan pedoman untuk audit sistem manajemen. Versi saat ini adalah ISO 19011:2018. Standar ini dikembangkan oleh Organisasi Internasional untuk Standardisasi.
Awalnya diterbitkan pada tahun 1990 sebagai ISO 10011-1 dan pada tahun 2002 mengambil penomoran ISO 19011 saat ini. Setiap internal auditor yang bertugas wajib memahami standar ini yang menjelaskan tentang :

(a) penjelasan yang jelas tentang prinsipprinsip audit sistem manajemen, (b) pedoman pengelolaan program audit, (c) pedoman pelaksanaan audit internal atau eksternal, (d) nasihat tentang kompetensi dan evaluasi auditor.

\section{Metode Penelitian}

Penelitian ini berjenis Deskriptif kualitatif. Data-data diperoleh dari hasil internal audit dan eksternal audit kemudian kedua data tersebut dibandingkan untuk menguji apakah ada temuan berulang yang disebabkan kurang efektifnya tindakan koreksi

\section{Hasil Penelitian dan Pembahasan}

\subsection{Hasil Penelitian}

Telah dilakukan internal audit menggunakan auditor-auditor internal dengan latar belakang sebagai berikut: 
Tabel 1. Profil Internal Auditor

\begin{tabular}{|l|l|l|}
\hline & Bidang Keahlian & $\begin{array}{l}\text { Lulus ISO } \\
19011 ?\end{array}$ \\
\hline A & S1 Kimia & Ya \\
\hline B & S1 Teknik Industri & Ya \\
\hline C & S1 Ekonomi & Ya \\
\hline D & S1 Bisnis & Ya \\
\hline E & S1 Kimia & Ya \\
\hline F & S1 Kimia & Ya \\
\hline G & S1 Teknik Industri & Ya \\
\hline H & S1 Teknik Industri & Ya \\
\hline I & S1 Teknik Industri & Tidak \\
\hline J & S1 Ekonomi & Tidak \\
\hline
\end{tabular}

Sumber: data diolah peneliti (2021)

Dari 10 auditor yang bertugas, masih ada 2 orang yang belum lulus pemahaman ISO 19011, dan keduanya ditugaskan sebagai observer. Adapun observer hanya diijinkan untuk mengamati proses audit. Adapun lead auditor (pimpinan auditor) yang ditunjuk sesuai dengan tingkat pemahaman adalah auditor A. Selanjutnya auditor A akan membagi tugas audit berdasarkan audit plan yang telah disiapkan. Penugasan auditor dibuat sedemikian rupa agar auditor yang bersangkutan tidak ada konflik kepentingan dengan departemennya sendiri. Sebelum kegiatan audit, dilakukan pertemuan pembukaan yang dihadiri oleh perwakilan masing-masing departemen dan seluruh internal auditor. Adapun jadwal audit yang telah disiapkan :
Tabel 2. Internal Audit Plan

\begin{tabular}{|c|c|c|}
\hline $\begin{array}{c}\text { Hari } \\
\text { ke- }\end{array}$ & Auditor & Departemen \\
\hline $\mathbf{1}$ & A, G, H, I & $\begin{array}{c}\text { Pembelian, } \\
\text { Penerimaan Bahan } \\
\text { Baku, } Q A \text { \& } Q C\end{array}$ \\
\hline $\mathbf{2}$ & B, C, F, J & $\begin{array}{c}\text { Penjualan, PPIC, } \\
\text { Produksi, Tank Farm }\end{array}$ \\
\hline $\mathbf{3}$ & D, E & $\begin{array}{c}\text { Gudang, Bagian } \\
\text { Maintenance, Utility }\end{array}$ \\
\hline
\end{tabular}

Sumber: data diolah peneliti (2021)

Para auditor diberikan waktu 2 hari untuk menyusun laporan audit dan mengumpulkannya kepada lead auditor serta menyampaikannya di pertemuan penutupan. Adapun ringkasan hasil temuan internal audit yang telah dilakukan diperlihatkan pada gambar di bawah ini:
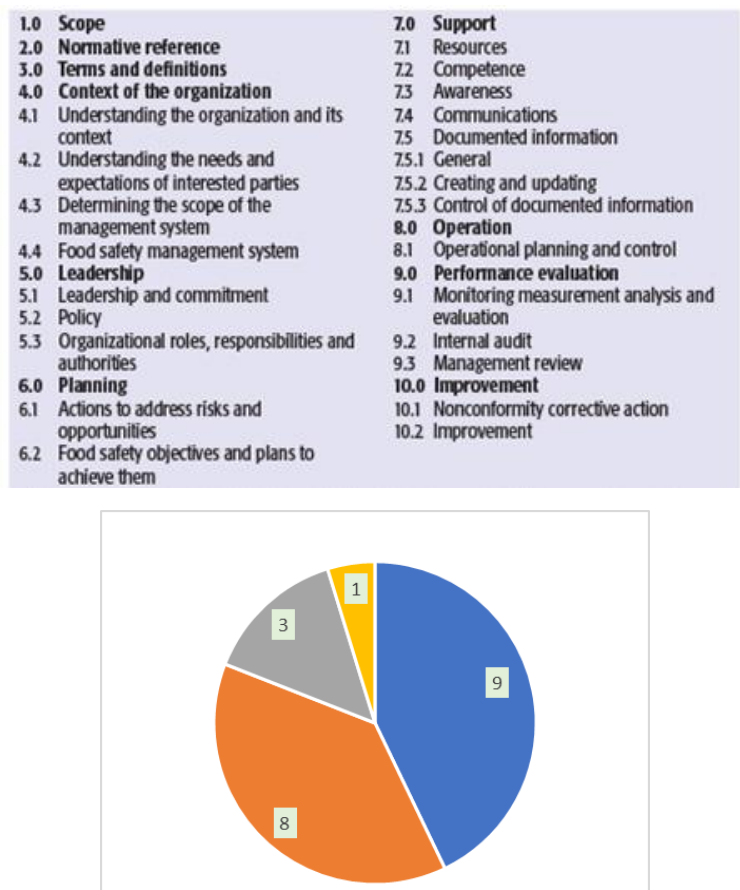

- Operation " Support " Leadership |- Improvement

Gambar 1. (Atas) Annex SL Klausul yang Diaudit; (Bawah) Temuan Audit 
Hasil audit menunjukkan ada 21 temuan minor yang terdiri atas 9 temuan di pengontrolan proses, 8 temuan terkait Support \& Documentation, 3 temuan tekair kebijakan dan 1 temuan terkait improvement. Adapun distribusi temuan internal audit dapat dilihat pada tabel di bawah ini:

Tabel 2. Distribusi Temuan

\begin{tabular}{|l|l|l|}
\hline No. & Temuan & Departemen \\
\hline 1 & Operation (9) & $\begin{array}{l}\text { Produksi \& } \\
\text { Penerimaan } \\
\text { Bahan Baku }\end{array}$ \\
\hline 2 & $\begin{array}{l}\text { Support \& } \\
\text { Documentation (8) }\end{array}$ & $\begin{array}{l}\text { Produksi \& } \\
\text { Maintenance }\end{array}$ \\
\hline 3 & Leadership (3) & QA \\
\hline 4 & Improvement (1) & QC \\
\hline
\end{tabular}

Sumber: data diolah peneliti (2021)

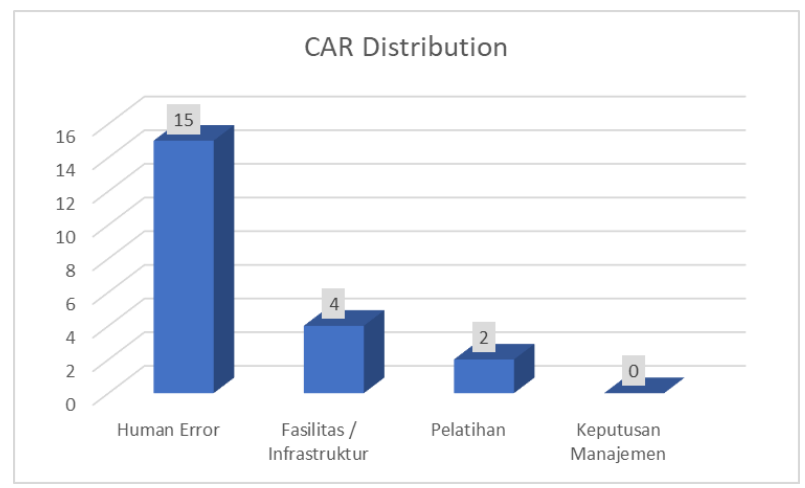

\section{Gambar 2. Distribusi Corrective Action Request (CAR) Berdasarkan Analisa Penyebab}

Hasil internal audit telah disampaikan kepada auditee yang bersangkutan. Manajer departemen akan melakukan analisa penyebab serta menentukan tindakan koreksi yang tepat untuk menutup akar masalah yang teridentifikasi. Dari CAR yang telah diisikan, didapati 15 kasus terjadi karena kurangnya konsistensi atau human error, 4 kasus terjadi karena fasilitas atau kondisi lingkungan sedangkan 2 kasus membutuhkan pelatihan lebih lanjut terhadap personil yang terlibat.

\subsection{Pembahasan}

Kesalahan manusia merupakan hal utama terjadinya penurunan kualitas atau produktivitas di berbagai industri. Meski tidak dapat sepenuhnya dihilangkan, faktor kesalahan manusia dapat dicegah mulai dari tahapan desain, dari prosedur, pelatihan dan juga lingkungan. Variabel-variabel tersebut dapat dimanipulasi sehingga mengurangi terjadinya hal tersebut. Oleh karena itu sangat penting memahami tipe-tipe perilaku manusia serta mengerti secara tepat dimana celah kelemahan dari sistem yang ada. Klasifikasi faktor penyebab kesalahan pekerja antara lain berbasis : pengetahuan, kognisi, nilai, refleksif, pengenalan kondisi dan keterampilan. Tindakan korektif yang disarankan untuk menutup temuan ini antara lain seperti: memberikan prosedur, instruksi, dan bantuan pekerjaan dengan jelas dan akurat; menerapkan rekayasa faktor manusia yang baik untuk sistem kontrol dan proses; 
memberikan pelatihan serta pengawasan / supervisi; meningkatkan komunikasi yang baik.

Pelatihan adalah upaya yang ditempuh organisasi untuk menyelesaikan permasalahan kompetensi yang terjadi sehingga dapat mencapai tujuan serta sasaran secara efektif dan efesien. Tujuan dari pelatihan adalah:

○ Perbaikan kinerja;

- Pemutakhirkan keahlian para pekerja sejalan dengan perkembangan teknologi;

○ Mempercepat pemenuhan kompetensi belajar bagi karyawan baru;

- Pemecahan masalah operasional;

- Kepentingan promosi; dan lain-lain

Selanjutnya tujuan pelatihan secara lebih spesifik yakni untuk membangun atau mengembangkan pengetahuan dan keterampilan pekerja guna mencapai tingkat yang diinginkan hingga mencapai kompetensi akhir yang diinginkan.

Pembenahan infrastruktur juga menjadi salah satu objek temuan yang disoroti dari hasil internal audit yang telah dilakukan. Beberapa infrastruktur seperti pintu Gudang, plastic curtain, GMP Room perlu diperbaiki agar tetap sesuai dengan pemenuhan standar ISO 22000.
Setiap departemen diberikan waktu antara $1-3$ bulan untuk menutup temuan internal audit tersebut sebelum dilaksanakan eksternal audit dari badan sertifikasi. Adapun eksternal audit dilakukan oleh 2 orang auditor yang sudah teregistrasi IRCA (International Register of Certificated Auditors) selama dua hari penuh dengan menggunakan skema sertifikasi yang diintegrasikan yakni ISO 22000 dan ISO 9001.

Tabel 3. Eksternal Audit Plan

\begin{tabular}{|c|c|c|}
\hline $\begin{array}{c}\text { Hari } \\
\text { ke- }\end{array}$ & Auditor & Departemen \\
\hline 1 & A \& B & $\begin{array}{c}\text { Pembelian (A), } \\
\text { Penerimaan Baku (A), } \\
\text { Gudang (B), } Q A \& Q C \\
(B)\end{array}$ \\
\hline 2 & A \& B & $\begin{array}{l}\text { Penjualan (A), PPIC } \\
\text { (A), Produksi (A), Tank } \\
\text { Farm }(B), \text { Bagian } \\
\text { Maintenance }(B), \\
\text { Utility }(B)\end{array}$ \\
\hline
\end{tabular}

Sumber: data diolah peneliti (2021)

Tidak ada ditemukan permasalahan yang sama dengan hasil temuan internal audit di sesi audit pihak eksternal. Temuan audit eksternal adalah tentang pengendalian serta evaluasi terhadap supplier / vendor termasuk dokumen-dokumen spesifikasi milik vendor yang belum sesuai dengan standar serta kurang konsistennya penilaian tahunan yang dilakukan oleh tim pembelian. 


\section{Kesimpulan dan Saran}

\subsection{Kesimpulan}

Internal audit yang dilakukan terbukti efektif sehingga permasalahan yang ditemukan secara internal tidak kembali berulang di eksternal audit, namun perlu dilakukan penguatan di sisi pemeriksaan internal audit terkait pengendalian supplier.

\subsection{Saran}

Perlu dilakukan supplier audit secara rutin untuk memastikan supplier/vendor tetap memenuhi peraturan dan persyaratan sistem yang berlaku.

\section{DAFTAR PUSTAKA}

Arvanitoyannis, I.S. 2009. HACCP and ISO 22000 - Application to Foods of Animal Origin. Penerbit John Wiley \& Sons

Lesmana, E. 2020. Cara Mudah Memahami dan Mengimplementasikan ISO 9001:2015 dalam Perusahaan Anda. Cetakan I. Penerbit IPB Press.

Mortimore, S. 1998. HACCP - A Practical Approach. Maryland: Penerbit Springer Science.

Spencer, K.H. 2004. The Internal Auditor at Work. Penerbit John Wiley \& Sons

Spencer, K.H. 2011. The Essential Guide to Internal Auditing. Penerbit John Wiley \& Sons
Witara, K. 2018. Cara Singkat Memahami Sistem Manajemen Mutu ISO 9001:2015 dan Implementasinya. Cetakan Pertama. Kawa Jawa Barat. Penerbit Jejak Publisher.

Zamzami, F. 2013. Internal Audit - Konsep dan Praktik. Yogyakarta : Penerbit Gajah Mada Press

Zuhrawati. 2009. Panduan Dan Kiat Sukses Menjadi Auditor ISO 9001. Cetakan 1 - Yogyakarta : Media Pressindo. 